\title{
Efficacy of gabapentin in the improvement of pruritus and quality of life of patients with notalgia paresthetica*
}

\author{
Ana Alice Wolf Maciel ${ }^{1}$ \\ Isabela Ortiz Laraia ${ }^{1}$
}

\author{
Paulo Rowilson Cunha ${ }^{1}$ \\ Flávia Trevisan ${ }^{2}$
}

\section{DOI: http://dx.doi.org/10.1590/abd1806-4841.20142777}

\begin{abstract}
BACKGROUND: notalgia paresthetica is a subdiagnosed sensory neuropathy presenting as a condition of intense itching and hyperchromic macule on the back that interferes with daily habits.

OBJECTIVES: To determine the efficacy of treatment of notalgia paresthetica using oral gabapentin, assessing the degree of improvement in itching and influence on quality of life. Moreover, to evaluate the signs and symptoms associated with notalgia paresthetica.

MeTHODS: We conducted an experimental, non-randomized, parallel, non-blinded study including 20 patients with clinical and histopathological diagnosis of notalgia paresthetica. After application of the visual analogue scale of pain adapted for pruritus and of the questionnaire of dermatology life quality index (DLQI), ten patients with visual analogue scale $>5$ were given treatment with gabapentin at the dose of $300 \mathrm{mg}$ / day for four weeks. The other ten were treated with topical capsaicin $0.025 \%$ daily for four weeks. After the treatment period, patients answered again the scale of itching.

RESULTS: The use of gabapentin was responsible for a significant improvement in pruritus $(p=0.0020)$. Besides itching and hyperchromic stain on the back, patients reported paresthesia and back pain. It was observed that the main factor in the worsening of the rash is heat.

CONCLUSION: Gabapentin is a good option for the treatment of severe itching caused by nostalgia paresthetica.

Keywords: GABA modulators; Primary treatment; Pruritus; Quality of life; Therapeutics
\end{abstract}

\section{INTRODUCTION}

The World Health Organization (WHO) defines quality of life (QL) as "individuals' perception on their position in life in the context of the culture and value system in which they live and in relation to their goals, expectations, standards and concerns." 1 Dermatologists frequently use intuitive aspects to evaluate the extent to which skin diseases affect their patients and to make decisions regarding the management of these diseases; however, patients may evaluate their QL differently from their physicians, which may lead to difficulties for patients to adhere to and follow treatment recommendations. ${ }^{2}$ The evaluation of patient's symptom-related QL is useful in treatment decision-making and allows patients to become more instructed and involved in their own care., ${ }^{3,4}$

Itching causes great suffering; thus, its impact on patient's QL may be profound. ${ }^{5}$ It is crucially important to quantify the QL of patients with notalgia paresthetica (NP), because they complain of great discomfort caused by intense itching, sometimes accompanied by pain. This disease decreases patients' phy- sical and professional performance, which impairs their social interactions and has a negative impact on patients' perception on their own health, including mental health.

NP, which is named after the terms notos (back), algos (pain), and parestesias, is a sensory neuropathy defined for the first time in 1934 and affects dorsal spinal nerves, more specifically the upper branches of T2-T6 nerves. ${ }^{6} \mathrm{NP}$ etiology has not been completely elucidated yet, but it is especially attributed to nerve impingement syndrome affecting the dorsal branch of spinal nerves.? A study that found the presence of at least one spinal disorder associated with NP in nine out of 12 patients confirmed that spinal nerve compression results from degenerative changes in the spine and that this contributes to NP pathogenesis. ${ }^{8}$ Another study evaluating $10 \mathrm{NP}$ patients observed that seven of them presented with associated degenerative changes in the vertebrae. ${ }^{9} \mathrm{An}$ investigative study involving $65 \mathrm{NP}$ patients conducted in Brazil and Germany in 2012 by Huesmannet

Conflict of interests: none. 
$a l^{10}$ found that $32.3 \%$ of patients showed radiological tests revealing spinal stenosis and $47.7 \%$ revealing spinal degeneration. Other causes of nerve involvement include trauma and accidents. ${ }^{11}$ However, other hypothesis to explain the etiology of this disease postulates that it would be a sensory neuropathy resulting from the compression of upper branches of peripheral thoracic nerves by muscle fibers. Since these branches run in a straight angle through the muscles, it is suggested that this makes nerves more vulnerable to impingement, which causes itching. ${ }^{9}$

With regard to the genesis of itching, microneurography studies have demonstrated that there is a small subset of $C$ nerve fibers that are sensitive to histamine and responsible for transmitting pruritus and not pain. It has been shown that these $C$ nerve fibers have spontaneous activity in patients with chronic itching. ${ }^{11,12}$ Thus, itching may be understood as an irritation of sensitive skin nerve endings due to the biochemical action of substances spread on skin, including histamine released, for example, by substance P..$^{12,13}$

Although the occurrence of itching is not rare, studies conducted so far provide little knowledge on clinical and laboratory findings. An important clinical finding characterizing NP is a hyperpigmented wellcircumscribed stain. Additionally, its more common symptom is itching on the mid-upper portion of the back in the distribution of T2-T6 dermatome that may be associated with other sensory damages such as paresthesia, hyperesthesia and pain. ${ }^{14-16}$ Savk et al studied $10 \mathrm{NP}$ patients, seven women and three men, ${ }^{9}$ who were asked about dermatological and neurological symptoms and family history for the disease. Afterwards, the affected area was subjected to biopsy and electromyography. None of the cases analyzed in the study presented with peripheral neuropathies, e.g., diabetes, nor had a positive history of NP. Hyperpigmentation in the dorsal area was observed in all patients. Pruritus was the common symptom in all cases. Moreover, only two patients complained of episodes of pain and only one patient described a feeling of burning on the affected site. These initial findings are suggestive of a neurogenic disorder. ${ }^{6,9}$

There are cases of NP treated with capsaicin or topical corticosteroids, botulinum toxin, and systemic gabapentin and oxcarbamazepine for pain relief. ${ }^{9,1720}$ Topical corticosteroids are usually inefficient unless a secondary inflammation is present. They act by stabilizing membranes and contribute to the suppression of ectopic neural pacemaker activity. ${ }^{18}$ Botulinum toxin type A may be efficient in several pain syndromes, including postherpetic neuralgia and trigeminal neuralgia, and even in cases of itching. However, further research is needed to confirm its efficacy in the treatment of NP. ${ }^{17}$
Due to its presumably neural origin, many treatments for NP consist of acting on the lesion or involvement in the spinal dorsal nerve. ${ }^{19}$ Antipruritic agents may be divided into antihistaminic, antiserotonergic, antiopioid, non-hormonal anti-inflammatory, phototherapy, and brain antiarrhythmic or anticonvulsant. ${ }^{20}$ Among these, brain antiarrhythmic or anticonvulsant drugs are indicated when itching has a neuropathic origin, i.e., the neural lesion unstabilizes the activity of electrical conduction at peripheral and central levels, as occurs in NP. ${ }^{21}$ Currently, the systemic drugs most used and that showed better results are those that act in the metabolism of gamma-aminobutyric acid (GABA), such as gabapentin and pregabalin. ${ }^{21}$ Thus, the treatment with anticonvulsants seems to be the most promising approach for neuropathic pruritus caused by NP. ${ }^{10}$

Gabapentin (1-aminomethyl)cyclohexyl]acetic acid) has the structure of the GABA neurotransmitter but does not interact significantly with this neurotransmitter or with any other neurotransmitter. ${ }^{22,23}$ Its basic role on the chain of pain generation would be grounded on its action on calcium channels by inhibiting ion entry, reducing glutamate levels, and acting also on the control of allodynic phenomena. ${ }^{24}$ The lipophilic characteristics of gabapentin allow for this substance to pass through the blood-brain barrier. ${ }^{25}$ It has anti-hyperalgesic action that reduces hyperexcitability of neurons of the dorsal horn of the spinal cord, which is the responsible for central sensitization, and has proven to be clinically useful in the control of ectopic discharges from injured peripheral nerve sites. ${ }^{26,27}$ In addition, it shows good results in postherpetic neuralgia and in some cases of neuropathic syndromes.

Tolerance to gabapentin is usually good, with no reports of significant hematologic, hepatic and dermatologic complications. ${ }^{28}$ Its adverse effects are directly related to the dose used, the most common being sleepiness ( $20 \%$ of patients), ataxia $(17 \%)$, nystagmus $(15 \%)$, and asthenia. ${ }^{22,29,30}$

Magalhães et al reported a case of NP that showed no improvement after being initially treated with hydrocortisone/pramoxin ointment $2.5 \%$. Topical treatment with capsaicin was refused by the patient. Thus, the treatment of choice was gabapentin at a dose of $300 \mathrm{mg}$ every night. Pruritus improved as early as one month after treatment..$^{29}$

Topical capsaicin is another currently used treatment choice. This substance is a compound coming from chilli extract and acts by running out neuropeptides of $C$ polymodal fibers that transmit itching from skin to the central nervous system. ${ }^{31-34}$ Capsaicin may be useful, but symptoms tend to reappear after treatment discontinuation..$^{33}$ Adverse effects of capsaicin, whose intensity depends on its concentration in drug 
formulation, result mainly from its local mode of administration and involve burning and erythema. These reactions may compromise treatment adherence; therefore, it is estimated that one out of 10 patients tend to drop out of therapy due to the presence of local symptoms. ${ }^{35}$ Thus, many patients prefer other forms of treatment.

Although the occurrence of NP is not rare, studies conducted so far provide little knowledge on clinical and laboratory findings. The main objective of this study was to investigate the efficacy of the treatment of NP using gabapetin by evaluating the degree of improvement in pruritus and the influence of gabapetin on the QL of NP patients compared to topical capsaicin.

\section{MATERIALS AND METHODS}

An experimental, non-randomized, parallel, non-blinded study was conducted with 20 patients aged from 20 to 60 years old and with clinical and histopathological diagnosis of NP treated at the dermatology outpatient clinic of Faculdade de Medicina de Jundiaí, located in Jundiaí, Brazil, from August 2011 to May 2012 (Figure 1). Patients presenting with renal dysfunction or contraindications to the use of gabapentin were excluded from the study. Considering a confidence interval of $95 \%$, a maximum error of estimate for visual analogue scale (VAS) scores of 1.5, and a standard deviation of 3.4, sample size was calculated to be 20 individuals.

The selected patients were informed by the investigators about the purpose of the research and about the confidentiality of personal information. After the participants signed a written consent form, the VAS of pain adapted for pruritus was administered to evaluate the intensity of itching. The VAS is composed of a $10-\mathrm{cm}$ line divided into a scale from 0 to 10 , and patients should indicate the score that best represents the intensity of their itching (Figure 2).

Participants also answered the Dermatology Life Quality Index (DLQI). DLQI is an instrument validated for use in Brazil and consists of a 10-item questionnaire divided into six domains: symptoms and feelings, daily activities, leisure, work/school, personal relationships, and treatment. Answers yielded scores from zero to three for each domain, and overall score is calculated as a simple sum of domain scores, with higher scores indicating worse healthrelated QL.

For didactic purposes, patients were divided into two groups, A and B. Patients included in group A should have a VAS score of at least five. The investigators decided to establish this inclusion criterion in order to prevent patients with mild complaints from receiving treatment with gabapentin, which has a hig- her risk of systemic side effects. Group A comprised 10 patients who underwent treatment with gabapentin at a dose of $300 \mathrm{mg} /$ day for four weeks.

Group B also comprised 10 individuals, but they underwent the standard topical treatment with daily doses of capsaicin $0.025 \%$ for four weeks.

After four weeks of treatment, patients answered again the VAS for calculating the degree of itching intensity and assessing their treatment response.

Data were subjected to statistical analysis and evaluation of clinical significance. Data for the variable "difference in VAS for the evaluation of pruritus ( VAS)" before and after the use of medication were tested for normality in each group using the ShapiroWilk method. Treatment effect was assessed by the paired Wilcoxon test. In spite of selection bias for the groups and lack of randomization, percentage variation between the groups was compared using the Mann-Whitney test. The result of this comparison should be carefully analyzed, because there was a great difference in mean initial VAS scores

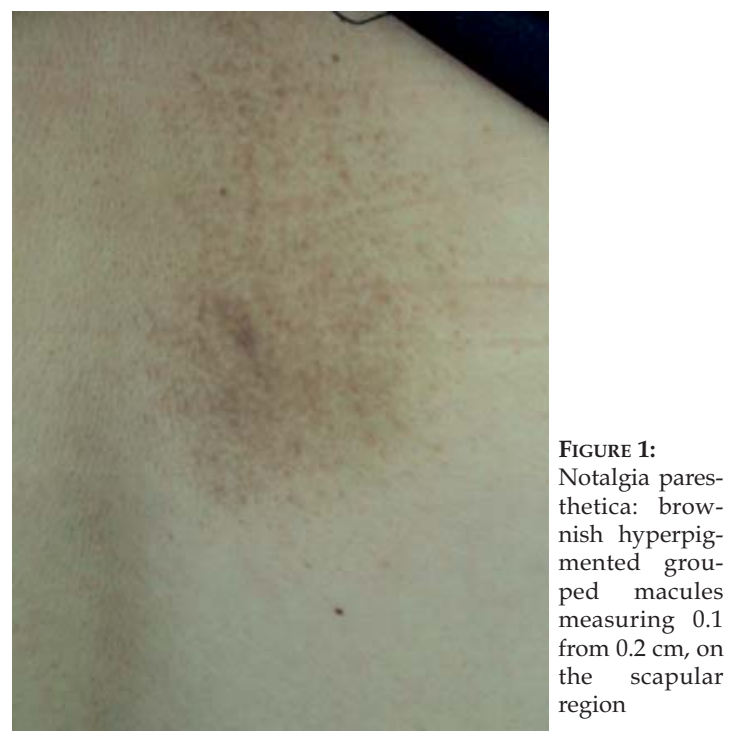

Visual Analog Scale

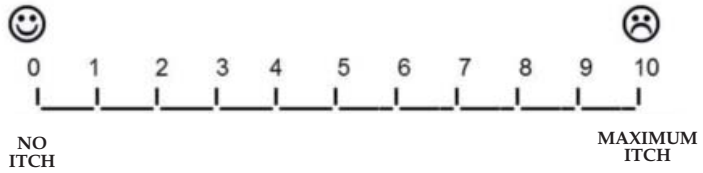

Figure 2: Visual analogue scale administered in this study to measure itching intensity 
Analyses were conducted using the Statistical Package for Social Sciences (SSPS) software (SPPS Inc., Chicago, USA), version 13.0. Significance level for statistical tests was set at $5 \%$.

\section{RESULTS}

Of the 20 patients analyzed in this study, 12 had already received previous and short treatment with capsaicin soon after disease diagnosis, but nine of them interrupted the treatment at the beginning due to intense burning.

A significant improvement in itching was observed in patients from group A, which was demonstrated by the decrease in mean VAS scores for itching. Before the treatment with gabapentin, mean VAS score was 9.5, and after treatment it decreased to 5.0 , with a standard deviation of nearly \pm 3.3 (Table 1 ). The $p$-value obtained $(p \approx 0.002)$ allowed to conclude that there was a statistically significant difference.

In addition, nine patient from this group reported an improvement in itching severity, and none of the patients showed a higher score for itching after treatment, and only one patient maintained the same score after medication (Table 2). All patients from this group reported mild gastric discomfort and only one patient reported dizziness.
A discrete improvement in itching severity was observed in group B, but it was less significant than that observed in the group treatment with gabapentin. Mean VAS initial score of the patients from this group was 3.00 and final score was 2.00, with standard deviation of \pm 2.3 (Table 1 ).

Six patients from this group did not report any change in itching severity even after topical administration of capsaicin; three patients reported an improvement in itching intensity, and one patient reported a worsening in the severity of itching symptoms. All patients from this group reported intense burning as a treatment effect. There was no significant difference in group B $(0.3125<\mathrm{p}<0.4375)$.

The 20 participants of the study also answered a questionnaire that evaluated the Dermatology Life Quality Index (DLQI). Seventy-five percent of patients were classified as having mild-to-moderate impairment in QL, and $10 \%$ of patients obtained scores that revealed severe impairment (Table 3).

A hundred percent of patients analyzed in this study presented with paravertebral or vertebral hyperpigmented spots associated with itching. The most common symptoms associated with itching and stains were local paresthesia in $60 \%$ of patients and back pain in $70 \%$. Moreover, $65 \%$ of patients reported worsening of the rash with heat (Graph 1).

TABLE 1: Descriptive analysis of VAS scores*

\begin{tabular}{lllll}
\hline & \multicolumn{2}{c}{ Group A } & \multicolumn{2}{c}{ Group B } \\
\cline { 2 - 5 } & Initial VAS & Final VAS & Initial VAS & Final VAS \\
\hline $\mathrm{Na}$ & 10 & 10 & 10 & 10 \\
Mean & 8.2 & 5.4 & 2.9 & 2.7 \\
Median & 9.5 & 5 & 3.0 & 2.0 \\
Standard deviation & 2.300 & 3.373 & 1.912 & 2.312 \\
Minimum score & 5 & 2 & 0 & 0 \\
Maximum score & 10 & 10 & 6 & 8 \\
\hline
\end{tabular}

* * Visual analogue scale of pain adapted for itching.

a Number of patients

TABLE 2: Comparison of initial and final VAS scores

\begin{tabular}{llcc}
\hline & Meaning & Na Group A & Na Group B \\
\cline { 2 - 4 } VASf $<$ Improvement in itching & 9 & 3 \\
VASf $>$ VASi & Worsening of itching & 0 & 1 \\
VASf $=$ VASi & Remained the same & 1 & 6 \\
\hline Total & & $\mathbf{1 0}$ & $\mathbf{1 0}$ \\
\hline
\end{tabular}

a Number of patients

$\mathrm{b}$ Visual analogue scale score for itching at the end of the treatment.

c Visual analogue scale score for itching before the treatment. 
TABLE 3: Scores for the Dermatology Life Quality Index (DLQI)

\begin{tabular}{lc}
\hline Description/Scores & $\begin{array}{c}\text { Percentage of } \\
\text { patients (\%) }\end{array}$ \\
\hline Without impairment (0-1) & 15 \\
Mild impairment (2-5) & 60 \\
Moderate impairment (6-10) & 15 \\
Severe impairment (11-20) & 10 \\
Extremely severe impairment (21-30) & 0 \\
\hline
\end{tabular}

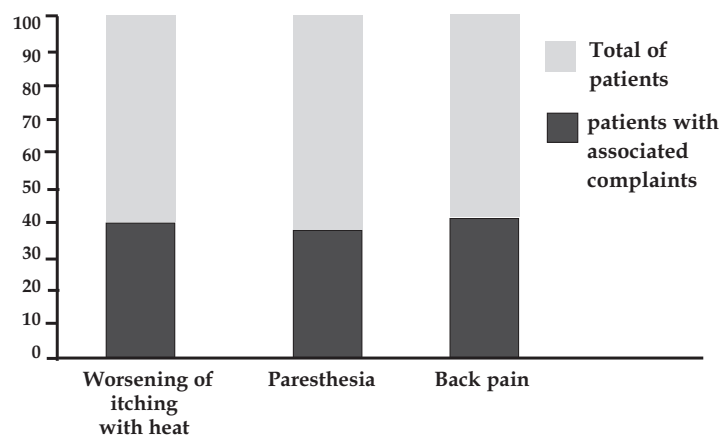

GRAPH 1: Graph of symptoms associated with notalgia paresthetica, in addition to itching and hyperchromic macule

\section{DISCUSSION}

It is extremely important to choose the proper approach and treatment for NP, because itching is an important symptom that may severely compromise patient's QL. ${ }^{36}$ Macule, which is often hyperpigmented and covers a great portion of patient's back, may interfere with daily habits and clothing. In the present study, $75 \%$ of patients showed DLQI scores compatible with mild-to-moderate impairment in QL, which demonstrates that NP have a small, although frequent, influence on patients' well-being.

Mean VAS scores for itching decreased from 9.5 to 5.0 in group A, treated with gabapentin, a finding that demonstrates that the use of gabapentin has been responsible for the improvement in itching observed in all patients from this group. The side effects of this drug were well tolerated.

Of the 10 patients from group B, who were given topical capsaicin, six patients maintained the same score for itching before and after treatment, and only three patients reported improvement. Additionally, all patients who used capsaicin reported intense burning, which may hinder treatment adherence very much.

Clinical manifestations of NP are characterized by clinical hyperpigmented stains associated with itching and paresthesia. ${ }^{37}$ Manifestations of NP range from invisible skin lesions to hyperpigmented circumscribed macule, as found in most patients. ${ }^{10}$ In the present study, $100 \%$ of patients presented with hyperpigmented macule on their back. The main symptom of NP is itching on the back, occasionally accompanied by pain, paresthesia, and hyperesthesia, resulting in skin hyperpigmentation on the affected area. ${ }^{20}$

In the patients analyzed, in addition to itching and hyperchromic macule on the back, paresthesia was reported in $60 \%$ of cases and back pain in a $70 \%$. This study found that the main factor of worsening of itching is heat, which was reported by $65 \%$ of patients. Many of them reported worsening of itching during summer and on days with high temperatures, and associate presence of sweat with disease worsening. One of the possible explanations for this finding is that itching and temperature are conducted by the same nervous fibers; therefore, an increase in temperature worsens itching, similar to what occurs in itching caused by atopic dermatitis.

It bears stressing that, although a statistical significance was observed in the evaluation of the effect of the treatment with gabapentin, this study has a patient selection bias, since groups were not randomly divided. Additionally, the Hawthorne effect cannot be ruled out, because there is an influence on patient's symptoms simply because they are being observed. Another study limitation was the impossibility of performing a blinded investigation, because the treatments we compared consisted of different forms of administration.

The statistical and methodological design of the present study had several difficulties, due to reasons common for several clinical trials. There was great difficulty in randomizing the groups, since there was a great variation in the measurement of symptoms between patients and even for the same patient at different periods of time. Furthermore, we used VAS scores in an attempt of turning a subjective symptom into numerical information to facilitate the analysis of treatment response.

There are no studies on the use of gabapentin for the control of itching in NP, treatment that was considered by the authors as belonging to category $\mathrm{D}$. Thus, we decided to prevent patients with low QL impairment and not very intense symptoms to receive a controlled drug that has several adverse effects.

\section{CONCLUSION}

In the present study, the use of oral gabapentin $300 \mathrm{mg}$ a day for the treatment of itching caused by NP showed to be efficient and led to a significant improvement in rates of itching intensity as assessed by the VAS. Capsaicin, a widely used drug in these cases, is effective but did not show statistically significant difference between pre- and post-treatment. Additionally, all patients reported burning throug- 
hout the entire topical treatment with capsaicin, which hindered treatment adherence. The only side effect produced by gabapentin was a mild gastric discomfort that did not interfere with treatment.

The most common associated symptoms, in addition to itching and macula on the back, were paresthesia and back pain; therefore, these symptoms should also be investigated in all patients with suspected NP. Guidance on using light clothes and staying at environments that help body temperature to remain low may be useful, since more than a half of patients report that itching worsens with heat.

\section{REFERENCES}

1. The WHOQOL Group 1995. The World Health Organization quality of life assessment (WHOQOL): position paper from the World Health Organization. Soc Sci Med. 1995;41:1403-9.

2. Welter EQ, Bonfá R, Petry V, Moreira LL, Weber MB. Relationship between pruritus and quality of life in patients on hemodialysis. An Bras Dermatol. 2008;83:137-40.

3. Lewis V, Finlay AY. Ten years of experience of the Dermatology Life Quality Index (DLQI). J Investig Dermatol Symp Proc. 2004;9:169-80.

4. Finlay AY, Ryan TJ. Quality of life measurement in Dermatology: a practical guide. $\mathrm{Br}$ J Dermatol. 1997;136:305-14.

5. Finlay AY. Dermatologists Should Better Integrate Quality-of-Life Measures to Inform and Improve Clinical Decision Making. Arch Dermatol. 2011;147:1157.

6. Astwazaturow M. Uber parasthetische neuralgien und einebesondere Form derselben-notalgia paraesthetica. Dtsch Znervenh. 1934; 133:188-96.

7. Savk E, Savk 0. On brachioradial pruritus and notalgia paresthetica. J Am Acad Dermatol. 2004;50:800-1.

8. Raison-Peyron N, Meunier L, Acevedo M, Meynadier J. Notalgia paresthetica: clinical, physiopathological and therapeutic aspects. A study of 12 cases. J Eur Acad Dermatol Venereol. 1999;12:215-21

9. Savk E, Savk 0, Bolukbasi 0, Culhaci N, Dikicioğlu E, Karaman G, et al. Notalgia paresthetica: a study on pathogenesis. Int J Dermatol. 2000;39:754-9.

10. Huesmann T, Cunha PR, Osada N, Huesmann M, Zanelato TP, Phan NQ, et al. Notalgia Paraesthetica: a descriptive two-cohort study of 65 patients from Brazil and Germany. Acta Derm Venereol. 2012;92:535-40.

11. Massey EW, Pleet AB. Notalgia paresthetica. JAMA. 1979;241:1464

12. Davidson S, Zhang X, Yoon CH, Khasabov SG, Simone DA, Giesler GJ Jr. The itchproducing agents histamine and cowhage activate separate populations of primate spinothalamic tract neurons. J Neurosci. 2007;27:10007-14.

13. King CA, Huff FJ, Jorizzo JL. Unilateral neurogenic pruritus: paroxysmal itching associated with central nervous system lesions. Ann Intern Med. 1982;97:222-3

14. Marcusson JA, Lundh B, Sidén A, Persson A. Notalgia paresthetica - puzzling posterior pigmentes pruritic patch. Acta Derm Venereol. 1990;70:452-4.

15. Springall DR, Karanth SS, Kirkham N, Darley CR, Polak JM. Symptoms of nostalgia paresthesica may be explaned by increased dermal innervation. J Invest Dermatol. 1991:97:555-61.

16. Freedberg IM, Eisen AZ, Wolff K, Austen KF, Goldsmith LA, Katz SI, editors. Fitzpatrick's Dermatology in General Medicine. 6th ed. New York: McGraw-Hill; 2003.

17. Weinfeld PK. Successful treatment of notalgia paresthetica with botulinum toxin type A. Arch Dermatol. 2007;143:980-2.

18. Devor M, Govrin-Lippmann R, Raber P. Corticosteriods suppress ectopic neuronal discharge originating in experimental neuromas. Pain. 1985;22:127-37.

19. Loosemore MP, Bordeaux JS, Bernhard JD. Gabapentin treatment for notalgia paresthetica, a common isolated peripheral sensory neuropathy. J Eur Acad Dermatol Venereol. 2007;21:1440-1.

20. Cunha PR, Delfini O. Prurido. Dermatologia Ibero-Americana Online. 2011;134.

21. Tyagi T, Sachin K, Amit K, Gunjan S. Pathophysiology and treatment of notalgia paresthetica - a sensory neuropathic syndrome of the back skin: an overview. Int J Pharm Bio Sci. 2010;1:1-8

22. Rowbotham MC. Treatment of neuropathic pain: perspectives on current options. In: Pain - an update review: refresher course syllabus. Washington, D.C: IASP; 2005 p.107-19.
This is a pioneering study on the treatment of NP that provides data to be used in clinical trials, with better investigation methodology and comparison with a placebo group. Although large samples of patients diagnosed with NP are difficult to obtain, studies with a greater number of patients will confirm hypotheses and help in the treatment of this still little understood disease. $\square$
23. Gidal BE. New and emerging treatment options for neuropathic pain. Am J Manag Care. 2006;12:S269-78.

24. Rose MA, Kam PCA. Gabapentin: pharmacology and its use in pain management. Anaesthesia. 2002;57:451-62.

25. Sindrup SH, Jensen TS. Efficacy of pharmacological treatments of neuropathic pain an update and effect related to mechanism of drug action. Pain. 1999:83:389-400.

26. Maneuf YP, Gonzalez MI, Sutton KS, Chung FZ, Pinnock RD, Lee K. Cellular and molecular action of the putative GABAmimetic, gabapentin. Cell Mol Life Sci. 2003;60:742-50

27. Pan HL, Eisenach JC, Chen SR. Gabapentin suppresses ectopic nerve discharges and reverses allodynia in neuropathic rats. J Pharmacol Exp Ther. 1999;288:1026-30.

28. Clivatti J, Sakata RK, Issy AM. Review of the use of Gabapentin in the Control of Postoperative Pain. Rev Bras Anestesiol. 2009;59:87-98.

29. Magalhães E, Mascarenhas AM, Kraychete DC Sakata RK. Gabapentin to Treat Sacral Perineural Cyst-Induced Pain. Case Report. Rev Bras Anestesiol. 2004;54:73-7.

30. Dahl JB, Mathiesen 0, Møiniche S. Protective premedication: an option with gabapentin and related drugs? An review of gabapentin and pregabalin in the treatment of postoperative pain. Acta Anaesthesiol Scand. 2004:48:1130-6.

31. Mccleane G. Topical analgesics. Anesthesiol Clin. 2007:25:825-39, vii.

32. Barbano RL, Herrmann DN, Hart-Gouleau S, Pennella-Vaughan J, Lodewick PA, Dworkin RH. Effectiveness, tolerability, and impact in quality of life of lidocaine patch in diabetic polineuropathy. Arch Neurol. 2004;61:914-8.

33. Brenner W, Gschnait F, Mayr WR. HLA B13, B17, B37 and Cw6 in psoriasis vulgaris: association with the age of onset. Arch Dermatol Res. 1978;262:337-9.

34. Kraemer MHS, Uthida-Tanaka AM, Oliveira VC. Early-onset of psoriasis in Brazilian patients: support for HLA-class I and class II analysis. In: 2nd Congress of the Federation of Immunological Society of Asia-Oceania. Italy: Monduzzi Editore, International Procedures Division; 2000. p. 69-73.

35. Breneman DL, Cardone JS, Blumsack RF, Lather RM, Searle EA, Pollack VE. Topica capsaicin for treatment of hemodialysis-related pruritus. J Am Acad Dermatol. 1992;26:91-4

36. Medicinanet.com.br [Internet]. Matsumoto FY. Prurido. 2008. [acesso 18 Out 2011] Disponível: http:// www.medicinanet.com.br/conteudos/revisoes/1453/prurido.html.

37. Durango A, Urbina M, Faria M. Notalgia parestésica: reporte de 8 casos. Dermatol. Venez. 2003;41:23-6

\author{
MAILING ADDRESS: \\ Flávia Trevisan \\ Rua Marechal Mallet, 181 - São Pedro \\ 83005-530 - São José dos Pinhais, PR \\ Brazil \\ E-mail: flaviatrevisan1@yahoo.com.br
}

How to cite this article: Maciel AAW, Cunha PR, Laraia IO, Trevisan F. Efficacy of gabapentin in the improvement of pruritus and quality of life of patients with notalgia paresthetica. An Bras Dermatol. 2014;89(4):570-5. 